\title{
Placebo pills for children
}

\section{A deeply bad idea}

And so another trend begins in America. This time it is placebo pills for kids.

On 1 June a company called Efficacy Brands (I'm not making this up) put cherry flavoured sugar tablets on sale on the web. The company was started by a mother with three young children, who has appeared on the morning television shows in the US to publicise her inspiration. For just under $\$ 6.00$ you can order a bottle of these pills to "treat" children when real medicine isn't appropriate and a hug and a kiss aren't enough. The pill is called Obecalp-placebo spelt backwards. How clever is that?

I first became aware of the power of placebos 30 years ago when I was an intern in a large US urban hospital. Our pharmacy stocked two "special” painkilling drugs, available by a doctor's prescription only. One came in a brilliant red capsule and the other was deep purple. The interns were instructed that these pills were for people who abused pain medications and were to be dispensed with care-and with a good story. It turned out that the red one was aspirin and the purple one was Tylenol (paracetamol), although you couldn't find those exact words anywhere on the labels, which had (in small print) the obscure generic constituents of the medications.

And sure enough, I had a number of patients who said to me that they simply had to have that red pill, or that purple one, insisting that it was the only thing that took their pain away.

If it is ever ethical to use a placebo-and I'm not sure that it is-this is an example of when it might be appropriate: helping someone with a chronic problem, using medicine with proved efficacy, one that is not too dangerous. And without completely lying about what's in it. This meets many, but not all, of the criteria set out in a recent $B M$ J article offering guidance for prescribing placebos (3 May, $p$ 1020).

In a randomised controlled trial in the same issue, Ted Kaptchuk and colleagues cleverly deconstructed the components of the placebo effect (3 May, p 999). They showed that an important part of how placebos work is the patient-practitioner relationship. In their study, the response rate went from $44 \%$ to $62 \%$ when the clinician added "warmth, attention, and confidence" when delivering placebo acupuncture to treat the symptoms of irritable bowel syndrome. It's a great demonstration of what psychiatrist and GP trainer Michael Balint called the effect of the "doctor as drug."

Doctors know that we have this drug available, and good doctors dispense it wisely and effectively. The power of reassurance, empathy, and confidence can go a long way towards helping patients with any number of complaints, and of course parents have a similar power to comfort and even heal their children.

While I can think of situations in which it might be appropriate for doctors to administer a placebo pill, I can't say the same for parents. The problems are numerous.

Firstly, whom are we treating here, children or their parents? If placebos are to work, the patients need to believe in them. Are doctors thus going to dispense these pills to the parents for their children, without telling them it is an inactive substance? Or is it left to the parents to determine that it is appropriate to trick their children into believing

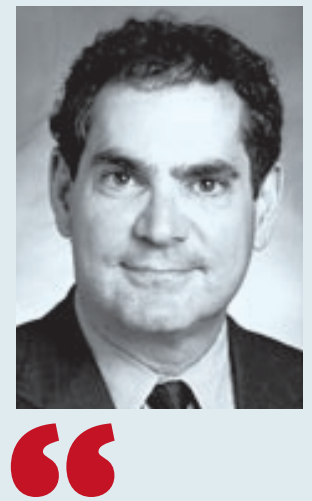

While I can think of situations in which it might be appropriate for doctors to administer a placebo pill, I can't say the same for parents

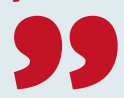

they are getting real medicine to help them?

Secondly, what will happen when the children become adolescents and find out that they were being sold a pill of goods, so to speak? Such a discovery can't be good for their trust in their parents, which is often at a nadir at that age anyway.

Thirdly, if parents use placebos to comfort their children, what are they teaching them? That tablets are the answer for all our aches and pains? And perhaps all our other problems too? Not advisable.

Finally, what makes us think that kids actually want medicine? If all children are like my three, who are now all teenagers, they won't take medicine when they are little, and they don't want it when they are big either.

And I don't buy the argument that giving a child a placebo pill is just like putting a plaster on a scratch: we know it doesn't make any difference, but we tell the kids that it does. Sure, there are kids who end up wanting a colourful plaster for every possible ache and injury, but I have never seen an adult addicted to plasters. I have seen very many adults who want a pill for every ill.

All in all, a placebo pill for children seems like a deeply bad idea, however well intentioned. Kids who are in pain, or sick, but don't require real medicine need someone to give them a hug or a kiss or, if a treat is indicated, maybe a sweet. But they don't need a sugar pill, and they certainly don't need to be deceived into thinking that it's the pill's magic, not Mum's or Dad's, that helped them feel better.

Douglas Kamerow is chief scientist, RTI International, and associate editor, BMJ dkamerow@rti.org 


\section{$B M J$ in "smug docs" storm}

\section{Can a media row over a BMJ editorial be blamed on newspaper journalists' misunderstanding of statistics? Rebecca Coombes investigates}

What was it about a recent $B M J$ editorial that caused a leading UK tabloid newspaper to condemn it as "outrageous" and displaying a "backwards, warped view"?

The article, inoffensively titled "Increasing diversity among clinicians," (BMJ 2008;336:1082-3) was written by Chris McManus, professor of psychology and medical education at University College London, and Hugh Ip, editor of Student BMJ. It argued against medical degree courses which deliberately lower entrance requirements in order to attract candidates from poorer backgrounds.

The 1000 word editorial went on to question the value of the $£ 190000$ a year scheme at King's College London, in which 50 of the 400 places are available for pupils from state schools in poor areas of the capital, even if they get three Cs at A level. "Is it worth our while to widen participation, particularly if this risks reducing standards?" asked Ip and McManus.

What rankled the Daily Mirror, one of the brigade of "red top" tabloid newspapers, was Ip and McManus's opening sentence. "UK medical students tend to come from higher socioeconomic classes, perhaps not surprisingly, as social class correlates with intellectual ability."

"Shame the smug docs" ran the headline to the Mirror's leader article, which blasted "cosy, smug doctors who claimed that comprehensive school pupils aren't bright enough to be medics." It wasn't brains that prevented "kids from ordinary backgrounds" from studying medicine; it was "hardship, explain to Ben Bradshaw fewer opportunities, blunted the difference between aspirations, old-school-tie 'correlates' and 'equates's networks and prejudice

like the views expressed in the $B M J$," went the comment piece.

The next day, the Daily Telegraph joined the fray. "Working classes 'lack intelligence to be doctors,' claims academic" ran the headline to its story. Health minister Ben Bradshaw was asked to give his opinion. "It's extraordinary to equate intellectual ability with social class. It is important that anyone who wants to study medicine is able to do so on ability rather than background," he said. The story led to 139 or more comments on the Telegraph website, including one reader who was intrigued to learn that Professor McManus once won an award for his study of testicles in ancient Greek sculpture: "Does this, I wonder, explain why his comments sound like a load of balls?"

For his part, Professor McManus was left rather bewildered by the reaction. "Why did the Telegraph put that in about the award? An assumption about the nature of professors, I guess, that they are crazy and unworldly." He thinks the Mirror ran with the story "because it is another way of putting this government on the ropes."

The $B M J$ editorial had been published more than two weeks before the media picked up on it-an ice age in Fleet Street terms. Then Professor McManus suddenly found himself fielding media requests from flagship $\mathrm{BBC}$ news programmes such as BBC2's Jeremy Vine Show and Radio 4's PMprogramme. He declined the invitations and is unrepentant about the views expressed in the editorial. "In fact, I would have been ruder about the King's research," he said, referring to a paper published in the same issue of the BMJby King's College London, outlining where its extended medical degree programme had been successful (BMJ 2008;336:1111-3). "I live near Arsenal Football Club and [the extended medical degree course] is like saying to Arsenal that $15 \%$ of the first team must live locally. Why do we want our doctors to be intelligent? Because we have a sneaking feeling that the most bright are those that will most help patients. There is evidence around to support that view. If we go in for social engineering we will have to pay the price."

McManus says he was trying to address "subtle issues that have now been reduced down to errors of statistics."

"I was not suggesting we should be selecting students on the basis of social class but on aptitude. As one nice comment on Telegraph talkboard said, just because Paris Hilton is rich doesn't mean she's intelligent. My point was that if you do select on aptitude then people from some social classes are more likely to be selected than others.
VOICF OF THF Minror Shame the smug docs

THE cosy, smug doctors who claimed that comprehensive school pupils aren't bright enough to be medics have exposed much that is wrong with their profession.

Unless other doctors roundly condemn the British Medical Journal's outrageous editorial, they will be accused of quietly condoning a backward, warped view.

Because it is plainly untrue that social class correlates with intellectual ability. Such snobbishness would be laughed out of any lecture theatre, never mind an operating theatre.

Hardship, fewer opportunities, blunted aspirations, old-school-tie networks and prejudice like the views expressed in the BMJ are reasons why more kids from ordinary backgrounds don't become doctors.

To assert that it is because they are not clever enough brings a noble profession into disrepute.

The British Medical Association publishes the journal so cannot wash its hands and hope the controversy just goes away. Millions of children deserve a public apology.

"Look at basketball players-one wouldn't select on height alone (any more than we would select on class alone for medical degrees). But once one selects for basketball ability, one shouldn't be surprised that they are taller than average, that their parents are also taller than average, as also are their children, who might be more likely to go on and become basketball players themselves." McManus believes that journalists picked up on the editorial because they "seem to love the posh-poor stereotypes. They have taken a complex problem and compressed it down to statements like 'all people are like this.' I suppose that is what we do in medicine: 'All 


\section{“It's extraordinary to equate intellectual ability with social class. It is important that anyone who wants to study medicine is able to do so on ability rather than background"}

\section{Ben Bradshaw}

surgeons are like this and all psychiatrists are identical."”

McManus said that health minister Ben Bradshaw's comments were "bizarre": "He wants to select both on ability and also on social class. But the two are ultimately incompatible if pushed to the limits. If the idea is so good, why doesn't King's take 100\% of students with lower grades-why just $15 \%$, if you want to select on the ground that they deserve to get ahead in society?"

$B M J$ editor Fiona Godlee did write to the Mirror, although her comments weren't published. In her letter she said: "The blunt fact is that poorer children in Britain are currently less likely to do well in A levels than richer children-for a whole host of complex reasons. And since medical schools select for high academic ability (as the public expects and patients deserve), the result is that fewer poor children will become doctors. The $B M J$ editorial suggests that trying to correct this at entry to medical school may be too little too late and that academic standards in medicine may suffer."

McManus did get some support in the media. On the Telegraph talkboard, reader Roger posted, "Someone needs to explain to Ben Bradshaw the difference between 'correlates' and 'equates."' Another reader, Mick Turner, objected to what he saw as bungled journalistic reporting of research: "It is only the [Telegraph $]$ headline that gives any degree of certainty and I'll bet that was written by the article writer and not the researcher. A safe conclusion then would be journalists are less likely to understand statistics than doctors. Or, to temporarily descend to the level of this journalist, journalists are thick."

In the Daily Mail, weekly columnist Martin Scurr, a GP, said the King's scheme was "just another example of government policy being based not on the evidence but on political ideology."

Professor McManus's phone is no longer red hot with media requests. "I suspect that this will gently die a death," he said. "Like all these arguments, there is much heat but little illumination."

Rebecca Coombes is a freelance journalist, London rcoombes@bmjgroup.com

\section{WHAT'S NEW ON BMJ.COM}

\section{BLOGS}

\section{http://blogs.bmj.com/bmj/}

Would you review a paper by your ex-husband? Conflicts of interests can be tricky to disentangle, says Liz Wager after learning that the UK government put the tax revenue from tobacco before the nation's health in the 1950 s. Everybody's got competing interests, she concludes in her blog. And perhaps no one more so than politicians, which does not inspire confidence in Joe Collier where the rationing debate is concerned: "When politicians wilfully stifle debate by refusing to use a crucially important word I get a sense of foreboding. Why should we trust a minister who uses this political ploy in an area as important as rationing?" he asks.

Meanwhile, Domhnall MacAuley attends a BMJ-supported, primary care conference in Tokyo and muses: "The enthusiasm and commitment was impressive and the excitement palpable as family medicine, a relatively new discipline in Japan, enters a phase of rapid growth." And the BMJ's current Clegg scholar, Anne Caley, who left a career in the City to study medicine, reflects on life in the $B M J$ office, where she is spending two months learning about medical journalism. Julian Sheather gives two cheers to Paul Biegler's recent analysis of autonomy, stress and depression and reflects on the awe and unease he feels towards antidepressants after spending years avoiding them.

Finally, Anna Donald, in her "From the other side" blog, delivers on a promise to explain why cancer is humbling. One of the reasons: "It makes you realise how little you really control.

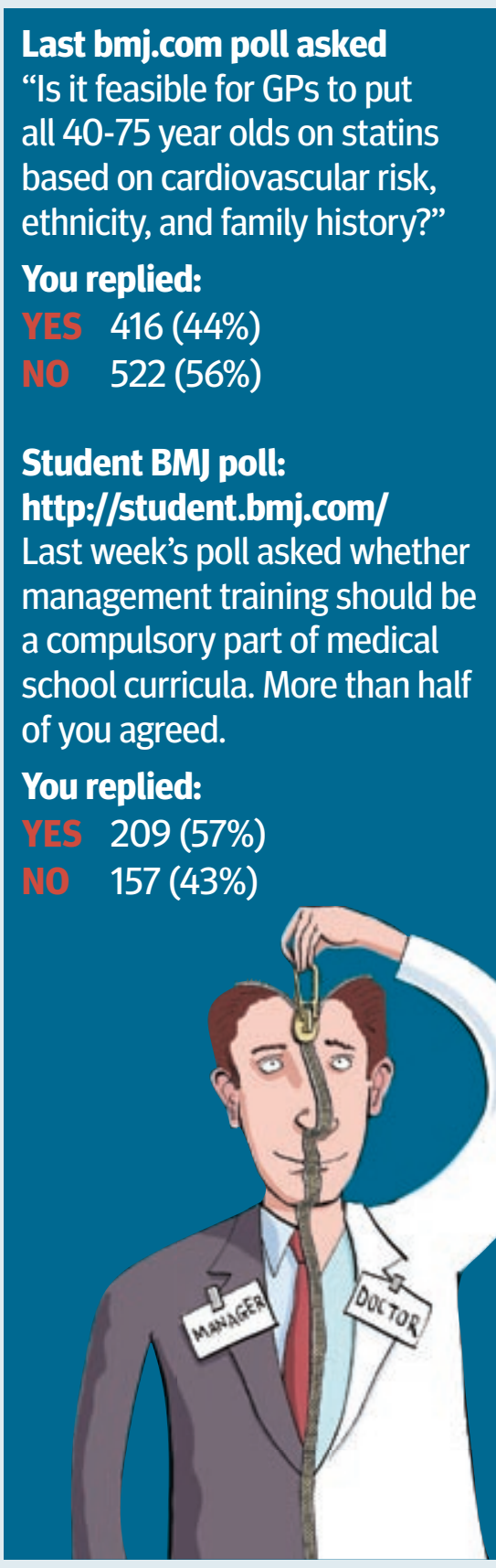

\section{MOST READ LAST WEEK}

Adherence to Mediterranean diet and risk of developing diabetes http://www.bmj.com/cgi/content/short/bmj.39561.501007.BE

Risk assessment and lipid modification for primary and secondary prevention of cardiovascular disease: summary of NICE guidance

http://www.bmj.com/cgi/content/short/336/7655/1246

How to interpret figures in reports of clinical trials

http://www.bmj.com/cgi/content/full/336/7654/1166

Emergency treatment of anaphylaxis

http://www.bmj.com/cgi/content/extract/336/7654/1141

Hormone replacement therapy and risk of venous thromboembolism in postmenopausal women

http://www.bmj.com/cgi/content/full/bmj.39555.441944.BE 